\section{A Community-Driven Social Marketing Campaign to Re- duce Childhood Obesity}

\section{Stephanie Pitsirilos-Boquín ${ }^{1}$, Kristy M Medina ${ }^{2 *}$, Alexa Squil- Iaro $^{3}$, Juan Carlos Gonzalez ${ }^{4}$, Dodi D Meyer ${ }^{5}$, Andres R Nieto ${ }^{2}$ and Patricia Hametz ${ }^{6}$}

${ }^{1}$ Zoe Healthcare Inc., Health Nashville, Tennessee, USA

${ }^{2}$ New York Presbyterian Hospital, Ambulatory Care Network, New York, USA

${ }^{3}$ Dashed, Inc., Business Development New York, USA

${ }^{4}$ Health and Wellness Division, Children's Aid Society, New York, USA

${ }^{5}$ Columbia University Medical Center, Community Pediatrics, New York, USA

${ }^{6}$ Montefiore Hospital and Medical Center, Pediatrics, New York, USA

\begin{abstract}
Background

Obesity disproportionately affects Latino children in the United States. In New York City, $40 \%$ of Latino children are overweight and obese, compared to $17 \%$ of children nationally. CHALK (Choosing Healthy \& Active Lifestyles for Kids) is a childhood obesity prevention program that was created by community members of the Washington heights and in wood neighborhoods of NYC to address increased prevalence of obesity.
\end{abstract}

\section{Community context}

Children are primarily Latino $(80.3 \%)$, with Dominican and Mexican roots. The majority of the community has limited English proficiency and $38.6 \%$ of Latino children live in poverty.

\section{Methods}

CHALK recruited community members to form a campaign, Vive

${ }^{*}$ Corresponding author: Kristy M Medina, New York Presbyterian Hospi tal, Ambulatory Care Network, New York, USA, Tel: +1 6462765408; E-mail: kmm9019@nyp.org

Citation: Pitsirilos-Boquín S, Medina KM, Squillaro A, Gonzalez JC, Meyer DD, et al. (2017) A Community-Driven Social Marketing Campaign to Reduce Childhood Obesity. J Community Med Public Health Care 4: 033.

Received: October 28, 2017; Accepted: December 26, 2017; Published: December 29, 2017 tu Vida/Live your Life, to create user-generated social marketing message and strategy. Campaign members engaged community entities including businesses, elected officials and individuals.

\section{Outcomes}

At the end of five years, CHALK had recruited 64 campaign participants. $58 \%$ reported they were actively promoting the program objectives. Through events, work of campaign participants, and minigrants, community members were exposed to the social marketing campaign. CHALK and the Task Force created a message in which the community felt ownership of the mission, vision and messages.

\section{Conclusion}

Through the work and support of the Vive tu Vida Task Force, CHALK created a culturally appropriate message. CHALK continued to disseminate the campaign and has expanded into venues beyond its original reach, including schools, faith-based organizations, non-profit organizations, and healthcare settings. Applying a socio-ecological framework and giving ownership and control to community stakeholders are crucial to creating a sustainable community social marketing health-promotion campaign.

Keywords: Community-based participatory research, Health promotion, Obesity, Pediatrics, Public health practice, Social marketing

\section{Background}

Childhood obesity is a major public health epidemic that disproportionately affects the Latino population in the United States. In $2009,22.5 \%$ of US Latinos ages $6-11$ years old were considered obese (BMI $>95 \%$ ) compared to $15.1 \%$ of Caucasian children [1]. Moreover in 2013, a reported $45.2 \%$ of children overall between 2-18 years old were considered overweight or obese (BMI $>85 \%$ ) [2].

The causes of childhood obesity are complex. Associations have been made between obesity, socio-economic status and the built environment-food deserts; prevalence of fast food establishments; walk ability; and safety-in addition to genetic predispositions [3,4]. Different cultural perceptions about weight can also impact eating and exercise behaviors, making a tailor-made approach to childhood obesity prevention essential. The socio-ecological model is a multi-factorial approach necessary to create cross-sector change in the prevention of childhood obesity within a community setting. This model considers the multiple factors that influence childhood obesity [5]. Interventions such as Shape Up Somerville, 5-4-3-2-1-GO! and 5210 Let's Go!, address obesity from a holistic, lifestyle perspective by engaging schools, businesses and communal organizations for social marketing message exposures, and in some cases, supportive environmental changes $[6,7]$. Shape up Somerville has demonstrated its efficacy with a decrease in Body Mass Index (BMI) scores over time [8].

While these interventions have proven successful in their respective communities, there is little in the literature which provides evidence for community-generated-owned and disseminated messages to combat childhood obesity. According to Kretzmann and McKnight, highlighting communities' capacities and not merely their needs can 
create a sustainable impact [9]. A community developed, community driven message could create a larger impact over time among residents as participants would have a voice in program development.

\section{Community Context}

The Washington Heights/Inwood (WaHI) community consists primarily of Dominican and Mexican immigrants. The majority of children, $80.3 \%$, are Latino; over $30 \%$ of all children are living in poverty, with the highest incidence of childhood poverty occurring in Latinos $(38.6 \%)[10,11]$. Nearly $40 \%$ of children are food insecure, with limited access to Emergency Food Providers including soup kitchens and food pantries. In 2011, over 39,000 individuals received SNAP benefits in the community [11].

Although recent data shows the rate of childhood obesity overall in New York City has declined, prevalence of obesity remains, on the whole, higher than the national average and steadfast in the Latino population [10]. WaHI are the epicenters of the NYC obesity epidemic. WaHI, which is made up of $71.7 \%$ Latino residents [2], has some of the highest percentages of children with obesity in NYC in addition to being a socioeconomically disadvantaged community with correspondingly high rates of poverty and food insecurity. Both these issues are connected to food access, malnutrition and obesity rates [12]. In 2011, 26.5\% of Latino children in Washington Heights aged 5-14 years were classified as overweight and obese, compared to only $16.1 \%$ of Caucasians in NYC [2].

Due to the large population of Dominican immigrants in the WaHI area, there are many "mom and pop" restaurants that serve Dominican-style meals. The national dish of the Dominican Republic, "La Bandera", consists of rice, beans, meat, and fried plantains. Generally, many starchy vegetables, like yucca, cassava, and plantains are consumed on a regular basis, and incorporation of dark greens is limited. Portions served both in the home and at restaurants are typically larger than recommended by the USDA.

Geographically, WaHI has a mixed terrain, with multiple, small public parks and recreation facilities, totaling 701 acres, or about one acre per 50 children. Despite the variety of open space, utilization may be hindered by perceived safety in the neighborhood. In 2013, 2,101 felonies were committed, with 869 classified as violent [10].

About 39\% of inhabitants have limited English proficiency, demonstrating a clear need for social marketing messaging and materials to be disseminated in Spanish more frequently than English [10].

\section{Methods}

\section{Community engagement and campaign creation}

In 2008, CHALK (Choosing Healthy \& Active Lifestyles for Kids) was created to combat childhood obesity in the WaHI community. Initially funded by a New York State Department of Health grant, it was a partnership between community participants and an academic medical center, relying on resources available to a large institution while drawing on the wisdom, experience and human capital of the community. It focused on creating a community-driven, culturally sensitive message that highlighted health promotion to schoolaged (5-12 years) children, avoiding a message that may create any stigmatization. Following the socio-ecological model, CHALK's efforts focused mostly on community, interpersonal, individual, and institutional levels of influences that affect obesity by providing nutrition education, partnering with community businesses, and providing grassroots organizations with funding to promote healthy lifestyles, to name a few examples.

At the initiation of the effort, a call for community participants was issued in order to ensure community engagement and collaboration in the creation of the message. This group became the Vive tu Vida/ Live Your Life Task Force. The Task Force members were a diverse group of individuals representing adult multidisciplinary community stakeholders. The Task Force members included community members, activists, and representatives from local partnering community based organizations, leadership of community churches, artists, and local food establishments. These Task Force members then led the coalition to create a captivating campaign title: "Vive tu Vida: Energía, balance, y Acción/Live your life: energy, balance, and action". Due to the large Latino community, it was critical to Task Force members to create the message first in Spanish, and then translate it into English. They chose English/Spanish cognates as descriptives, with the idea that the more similar the English and Spanish message was, the better the community would receive it. CHALK assisted the Task Force with the development of the slogan and provided formal training to the key Task Force members in social marketing.

The Community Task Force identified optimal public health messaging for the Washington heights community. They expanded the "8 Healthy Habits of Kids" from the healthy children healthy futures program [13] to the "10 healthy habits of kids" (Figure 1). The social marketing campaign focused on one habit per calendar month; the other two months promoted the overall campaign. Messages were piloted with several small focus groups with selected children, parents, and organizations before being mass distributed.

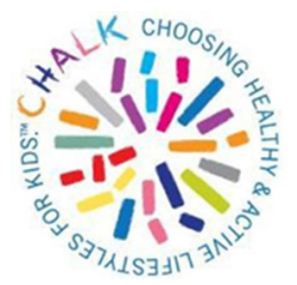

Figure 1: Social marketing 10 healthy habits for kids.

January: Be physically active every day

February: Eat plenty of vegetables and some fruit every day

March: Get enough sleep and eat breakfast

April: Switch to low-fat ( $1 \%$ or less) milk, cheese, and yogurt

May: Do something healthy every day that makes you feel good

June: Drink water instead of soda or juice

September: Turn off the screens and Live your Life!

October: Snack on healthy foods

November: Eat smaller amounts

December: Eat less fast food

The "10 healthy habits" became CHALK's program objectives, and together with the Task Force members, CHALK co-organized the community campaign and coalition to combat childhood obesity on the ground level, enlisting businesses and organizations, and engaging community residents. Outcomes of interest included number of community businesses that agreed to sign the CHALK/Vive tu Vida campaign pledge; number of community members who attended 
large-scale health promotion events; frequency of healthy habit use amongst community campaign participants; and use of healthy habit messaging after year 5 of the Vive tu Vida campaign (Figure 2).

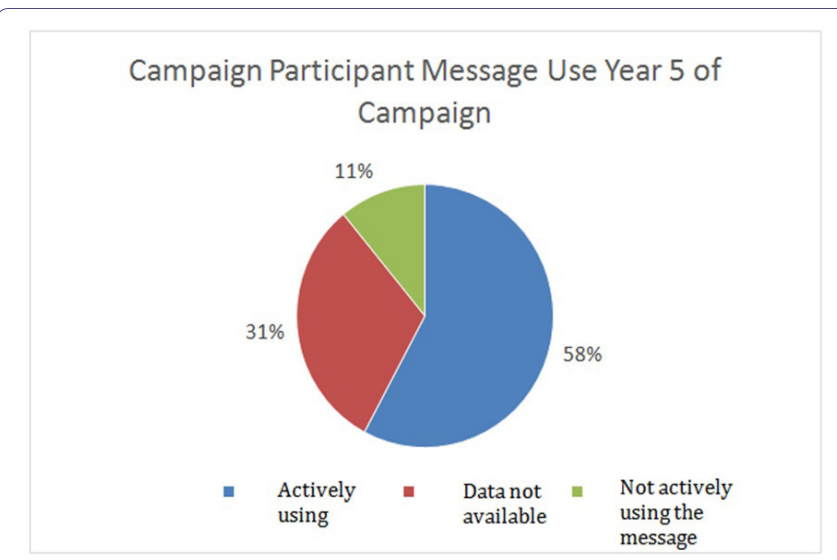

Figure 2: Campaign participants message use years 5 of campaign.

Business recruitment \& school participation: After messages were created, the Task Force created a kit to recruit local businesses and individuals to join the Vive tu Vida/Live your life campaign. The kit included a pledge, which committed the organization or business to promoting at least one of the 10 healthy habits of kids in the community. Once organizations, businesses, or individuals joined the campaign, they were given materials to promote all 10 healthy habits. Monthly healthy habit handouts were created in English and Spanish at a $5^{\text {th }}$ grade reading level to be dispersed through Task Force individuals and community businesses to all partners including businesses and schools. Baseline surveys were administered at the time the pledge was signed, with questions pertaining to the usage of the 10 habits of healthy kids messaging.

Schools promoted the 10 habits of healthy kids by distributing newsletters, creating bulletin boards and tailored nutrition education classes to communicate the message to children, staff and parents. Fitness organizations would incorporate healthy habit messaging and distributed promotional materials to community members. Businesses and individuals tailored the Vive tu Vida/Live your life message to suit their specific needs; for example, local grocers used "shelf-talkers" to promote water instead of soda or juice at a food store or bodega. At the same time, the Task Force met monthly to plan larger, community-wide events. In the first four years, CHALK/Vive tu Vida hosted three large events attracting up to 800 youth each for nutrition education and physical activity.

Mini-grants: Task Force members also worked to create sustainable, neighborhood change. CHALK awarded mini-grants ranging from $\$ 1,500-\$ 5,000$ to non-profit organizations for initiatives targeted to school-aged children and families in WaHI. Project proposals were reviewed and funded based on alignment with CHALK's social marketing messages and program objectives. Applicants could be granted multiple times and business members were encouraged to adapt CHALK/Vive tu Vida's message to best suit their needs.

\section{Outcomes}

Business participation: CHALK was able to reach many individual community members through direct programming such as events, mini-grants and marketing including the Vive tu Vida campaign and materials. Children from partner schools would visit Vive tu Vida campaign partners and either see CHALK promotional material or participate in hosted events. After four years, 64 businesses were actively engaged in the Vive tu Vida/Life your Life campaign. The largest number of participants (14\%) were from fitness businesses in the community, with community based-organizations making up another large portion (13\%) (Figure 3).

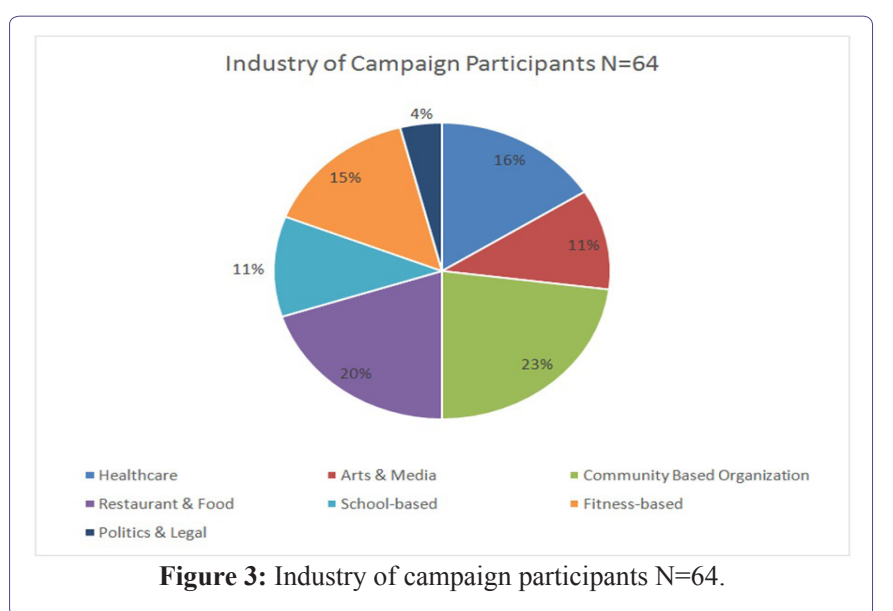

Of the 64 campaign participants, $75 \%$ responded to a one-year post survey. $43.7 \%$ of responders reported that they had promoted at least one of the 10 healthy habits of kids and provided examples. For example, bodegas promoted healthier snacks by providing healthier checkout items; instead of candies and packaged items, participants stocked fruits by the checkout registers.

Of the 64 participants, $68.7 \%(\mathrm{n}=44)$ responded to a second year follow up survey about campaign message usage. $58 \%(n=37)$ reported that they were actively using the message and $11 \%(n=7)$ responded that they were not, as shown in figure 3.

Campaign participants promoted the message and integrated healthy habits in a variety of ways including: traditional forms of advertising such as billboards on highways, signs in supermarket aisles, physical activity programming, and encouraging active community lifestyles. Others adopted healthy snack policies in their child programming or created healthy menu options for customers.

Mini-grants: Seventeen organizations, businesses and artists received mini-grants from $\$ 1,500-\$ 5,000$ each over three years (some one time grants, others recurring), reaching more than 2,000 individuals. Mini-grant initiatives have included Saturday morning early literacy workshops with a healthy breakfast; community dance classes, walking, running, and cycling teams; summer play streets for children; and nutrition and cooking class workshops for congregants at a community church. Two businesses were not able to execute their grant after it was awarded. One, a media production business, was not able to secure a slot on public television programming so instead created videos for the campaign that aired on other shows. The second was a restaurant, which closed down in its second grant cycle.

Electronic message dissemination: Staff at the academic medical center created a bilingual website, chalkcenter.org, to electronically distribute the CHALK/Vive tu Vida campaign materials, and provide community updates and event information. CHALK's implementation 
guide, including school toolkit and clinical handbook, was available for download with over 22,000 visits during the last year of the Vive tu Vida Campaign. Both website visits and toolkit downloads are tracked monthly.

Built environment: Task Force members focused on the built environment to ensure sustainability of the program. Together they successfully advocated to the local community board to open a seasonal Greenmarket in the neighborhood. The Greenmarket, operated by Grow NYC, promotes local, seasonal food, and accepts Supplemental Nutrition Assistance Program (SNAP) and Women Infants and Children (WIC) dollars. It operates once a week June-November, and serves 1,000 customers weekly, and continues to bring fresh produce to the neighborhood. In addition, CHALK continues to provide nutrition education there.

\section{Interpretation}

By elevating and promoting the community voice with the work and support of the Vive tu Vida campaign Task Force, CHALK/Vive tu Vida was able to create a culturally appropriate message that focused on health promotion. The Task Force afforded the community a space to express concerns about typical obesity prevention efforts, and rectify those issues when designing their own model. Giving the community ownership of this effort was essential to success; community members felt ownership to and investment in the mission, vision, and messages that they created.

Initially, it was important to engage with local businesses in the neighborhood to establish credibility and visibility in the community. While the majority of campaign participants promoted the " 10 Habits of Healthy Kids", promotion styles varied. Additionally, businesses were not required to promote all 10 habits, as they may not have related directly to their business needs.

Since schools are epicenters of a community, collaboration with elementary schools has been key to dissemination of the message and campaign. CHALK's school program utilizes the Vive tu Vida messaging and has created a healthy lifestyles curriculum, Classroom Connections, which is mapped to Common Core Learning Standards (CCLS). Additionally, CHALK's adopted the Just Move ${ }^{\mathrm{TM}}$ in-class activity cards that promote kinesthetic learning with quick bursts of activity throughout the day. This program has been proven to increase physical activity to exceed the New York State Physical Education mandate of 150 minutes per week [14]. CHALK's school program implementation and evaluation was captured via an Environmental Scan Survey, which evaluates 4 years of school wellness environment throughout the intervention. CHALK in the schools has been able to increase awareness and implementation of wellness policies, increase health promotion, and sustainable environmental changes to promote healthy lifestyles among partnered district 6 schools.

However, by year 5 , only $58 \%$ of campaign participants were actively promoting the 10 healthy habits. Also, by that time, city-wide organizations were focusing on providing resources and incentives for owners of large businesses. Therefore, CHALK/Vive tu Vida focused on school and clinical settings, merging with a school-based obesity prevention program, in addition to continuing the community work, and even extending to the hospital's outpatient clinics. This ensured that the program disseminated consistent obesity prevention health messaging across the continuum of a child's life including the community, school, faith-based organizations, and clinical pediatric practices.

CHALK has been involved in community development opportunities throughout the neighborhood to create a more sustainable change. Permanent neighborhood fixtures like greenmarkets play streets, bike lanes and community gardens will help keep programming alive and encourage community members to participate in obesity prevention/ health promotion activities as a part of daily life. Engaging other stakeholders has not only provided a rich environment for collaboration and collective impact, but it also avoids duplicating efforts of larger, city-wide organizations.

The CHALK program continued to disseminate the 10 healthy habits created by the Vive tu Vida campaign and focus on community building and engagement. The social marketing calendar is used throughout all aspects of CHALK programming, evolving its message and tailoring it to other target audiences. The campaign and our community driven initiative have been critical in continued development and expansion of the obesity prevention efforts.

\section{Acknowledgement}

This research was supported by the New York State Department of Health, Division of Chronic Disease Prevention and Adult Health, contract \#C022499.

\section{References}

1. Ogden CL, Carroll MD, Kit BK, Flegal KM (2012) Prevalence of obesity and trends in body mass index among US children and adolescents, 19992010. JAMA 307: 483-490.

2. Citizens Committee of Childrens (2015) Keeping Track of New York City's Children, (11 th $\mathrm{edn})$. Citizens Committee of Childrens, New York, USA.

3. Van Hulst A, Roy-Gagnon M-H, Gauvin L, Kestens Y, Henderson M, Barnett $\mathrm{T}$ (2015) Identifying risk profiles for childhood obesity using recursive partitioning based on individual, familial, and neighborhood environment factors. Int J Behav Nutr Phys Act 12: 17.

4. Roux D, Ana V, Mair C (2010) Neighborhoods and health. Annals of the New York Academy of Sciences 1186: 125-145.

5. Kersh R, Stroup DF, Taylor WC (2011) Childhood obesity: a framework for policy approaches and ethical considerations. Prev Chronic Dis 8: 93.

6. Longjohn MM (2004) Chicago project uses ecological approach to obesity prevention. Pediatr Ann 33: 55-57, 62-63.

7. Rogers VW, Hart PH, Motyka E, Rines EN, Vine J, et al. (2013) Impact of Let's Go! 5-2-1-0: a community-based, multisetting childhood obesity prevention program. J Pediatr Psychol 38: 1010-1020.

8. Economos CD, Hyatt RR, Must A, Goldberg JP, Kuder J, et al. (2013) Shape Up Somerville two-year results: a community-based environmental change intervention sustains weight reduction in children. Prev Med 57: 322-327.

9. Kretzmann JP, McKnight J (1993) Building communities from the inside out: A Path toward finding and mobilizing a community's assets. Center for urban affairs and policy research, Illinois, USA.

10. King L, Hinterland K, Dragan KL, Driver CR, Harris TG, et al. (2015) Community health profiles 2015 , manhattan community district 12 : Washington heights and Inwood. New York City Department of Health and Mental Hygiene, New York, USA. 
Citation: Pitsirilos-Boquín S, Medina KM, Squillaro A, Gonzalez JC, Meyer DD, et al. (2017) A Community-Driven Social Marketing Campaign to Reduce Childhood Obesity. J Community Med Public Health Care 4: 033.

- Page 5 of 5 -

11. Centers for Disease Control and prevention (2011) Obesity in K-8 students - New York City, 2006-07 to 2010-11 school years. Morbidity and mortality weekly report (MMWR), Atlanta, USA. Pg No: 60: 1673-1678.

12. Townsend N, Foster C (2013) Developing and applying a socio-ecological model to the promotion of healthy eating in the school. Public Health Nutr 16: 1101-1108.
13. Jarpe-Ratner E, Zamula A, Meyer D, Nieto A, McCord M (2013) The healthy schools healthy families program: physical activity integration into elementary schools in New York City. J Community Med Health Educ 3: 194.

14. Healthy Directions I (2015) Healthy Children Healthy Futures. Healthy Directions I, New York, USA. 